\title{
Bone marrow cytomorphological changes in patients co-infected with visceral leishmaniasis and human immunodeficiency virus
}

\author{
Alana Jocelina Montenegro de Castro ${ }^{\top}$ \\ Romelia Pinheiro Gonçalves ${ }^{2}$ \\ Maria Helena da Silva Pitombeira ${ }^{3}$ \\ 'Pathology Department, Universidade \\ Federal do Ceará - UFC, Fortaleza, CE, Brazil \\ 2 Department of Clinical Analysis and \\ Toxicology, Universidade Federal do \\ Ceará - UFC, Fortaleza, CE, Brazil \\ 3 Department of Clinical Medicine, \\ Universidade Federal do Ceará - UFC, \\ Fortaleza, CE, Brazil
}

\begin{abstract}
Conflict-of-interest disclosure: The authors declare no competing financial interest
\end{abstract}

Submitted: 10/18/2011

Accepted: 10/21/2011

\section{Corresponding author: \\ Romelia Pinheiro Gonçalves \\ Departamento de Análises Clínicas e \\ Toxicológicas, Universidade Federal do Ceará - UFC \\ Rua Capitão Francisco Pedro 1210 \\ Rodolfo Teófilo \\ 60430-370 - Fortaleza, CE, Brazil \\ romelia.pinheiro@pq.cnpq.br}

www.rbhh.org or www.scielo.br/rbhh

DOI: 10.5581/1516-8484.20110129
Visceral leishmaniasis (VL) is a severe systemic infectious disease. ${ }^{(1)}$ It has been recognized as an opportunistic disease in patients infected with human immunodeficiency virus (HIV). ${ }^{(2,3)}$ The analysis of the bone marrow of patients co-infected with VL and HIV showed dysplasia of erythroid, granulocytic and megakaryocytic lineages (Figure 1), besides the presence of plasmacytosis, cytoplasmic bodies, hemophagocytosis, granuloma and intracellular and extracellular leishmania amastigotes (Figure 2). These findings are found in the analysis of bone marrow of patients coinfected with HIV and VL; knowledge of these findings may be useful for the diagnosis and prognosis of patients.

Keywords: HIV infections; Bone marrow examination; Leishmaniasis, visceral; AIDS-related opportunistic infections

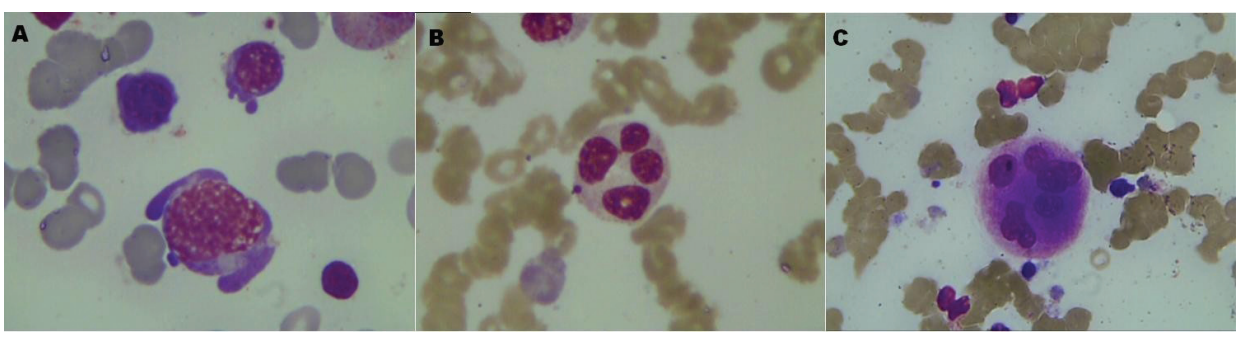

Figure 1 - Dysplastic changes in erythroid, granulocytic and megakaryocytic lineages in marrow aspirate of patients co-infected with visceral leishmaniasis and human immunodeficiency virus on Leishman stain (magnification: 1000x) (A) dyserythropoiesis; (B) dysgranulopoiesis; (C) dysmegakaryopoiesis

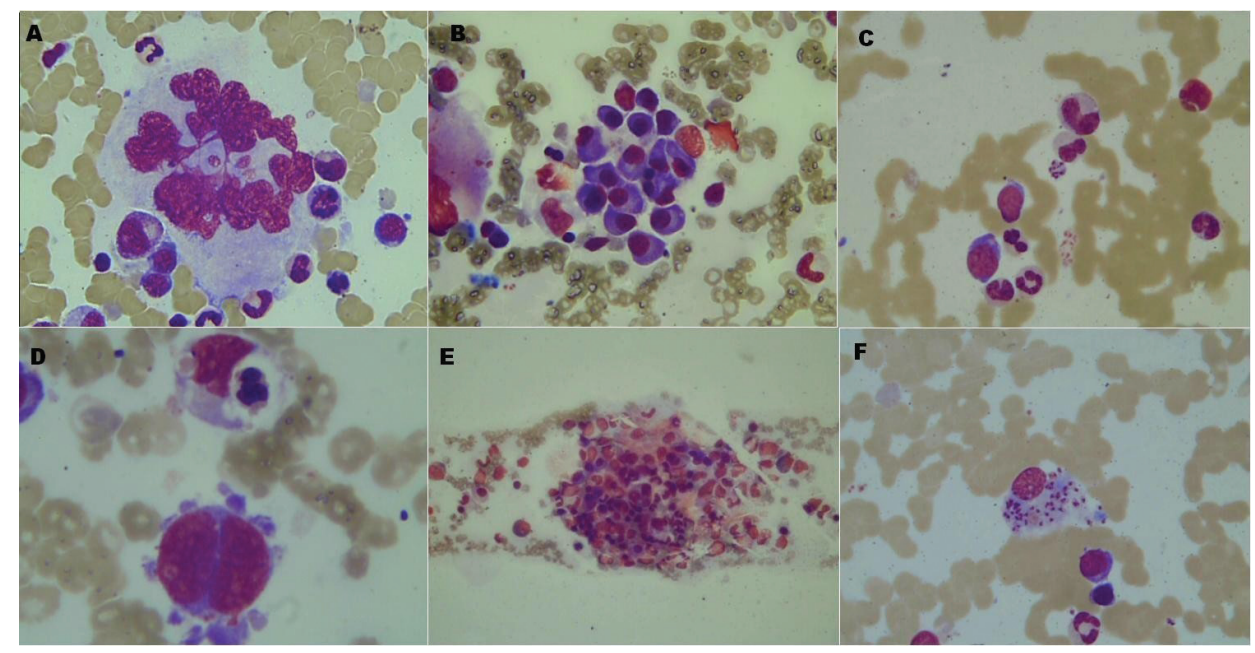

Figure 2 - Bone marrow cytomorphological changes in patients co-infected with visceral leishmaniasis and human immunodeficiency virus on Leishman stain (magnification: 1000x) (A) multiple lobulated megakaryocyte; (B) Plasmacytosis; (C) Cytoplasmic body - extracellular leishmania amastigotes; (D) Hemophagocytosis and dysmegakaryopoiesis; (E) Granuloma; (F) leishmania amastigotes phagocytosed by macrophages

\section{References}

1. Jawhar NM. Visceral Leishmaniasis with an Unusual Presentation in an HIV positive patient. Sultan Qaboos Univ Med J. 2011;11(2):269-72.

2. Daher EF, Fonseca PP, Gerhard ES, Leitão TM, Silva Júnior GB. Clinical and epidemiological features of visceral leishmaniasis and HIV co-infection in fifteen patients from Brazil. J Parasitol. 2009;95(3):652-5 3. Alexandrino-de-Oliveira P, Santos-Oliveira JR, Dorval ME, Da-Costa FC, Pereira GR, da Cunha RV, et al. HIV/AIDS-associated visceral leishmaniasis in patients from an endemic area in Central-west Brazil. Mem Inst Oswaldo Cruz. 2010;105(5):692-7. 